\title{
PENGARUH MOTIVASI DAN DISIPLIN KERJA TERHADAP KINERJA KARYAWAN DI PT. HASIL RAYA INDUSTRIES KARAWANG
}

\author{
Adi Komarudin ${ }^{1}$ Budi Rismayadi ${ }^{2}$ Suroso $^{3}$ \\ 2budi.rismayadi@ubpkarawang.ac.id \\ ${ }^{3}$ suroso@ubpkarawang.ac.id
}

\begin{abstract}
ABSTRAK
Penelitian ini memiliki tujuan untuk mengetahui apakah ada pengaruh parsial dan simultan antara motivasi dan disiplin kerja terhadap kinerja karyawan di PT. Hasil Raya Industries Karawang. Penelitian ini dilakukan dengan menggunakan metode deskriptif dan verifikatif, yaitu dengan mengumpulkan data, menyajikan data, menganalisis data, dan melakukan pengujian hipotesis, serta membuat kesimpulan dan saran. Sample dikumpulkan dengan metode Accidental sampling. Teknik analisis data yang digunakan Analisis jalur ( Path Analysis ). Dari hasil analisis data penelitian diperoleh hasil terdapat hubungan antara motivasi dengan disiplin kerja. Untuk hasil nilai person correlation mempunyai nilai yang positif. untuk pengaruh parsial motivasi terhadap kinerja karyawan disimpulkan bahwa $\mathrm{H} 0$ ditolak. untuk pengaruh parsial disiplin kerja terhadap kinerja karyawan dapat disimpulkan bahwa H0 ditolak. pengaruh simultan motivasi dan disiplin kerja terhadap kinerja karyawan dapat disimpulkan bahwa $\mathrm{H}_{0}$ ditolak. Motivasi dan disiplin kerja terhadap kinerja karyawan memiliki pengaruh secara simultan.
\end{abstract}

Kata kunci : Motivasi, Disiplin kerja, dan Kinerja karyawan.

PENDAHULUAN

Sumber daya manusia merupakan aspek yang penting untuk menunjang produktivitas sebuah perusahaan agar mampu bertahan di dalam ketatnya persaingan saat ini. Oleh karena itu, sebuah perusahaan harus mampu mengelola sumber daya manusianya dengan baik agar dapat meningkatkan produktivitas di perusahaan tersebut.

Perusahaan dan karyawan merupakan suatu hal yang saling membutuhkan satu sama lain. Keberhasilan suatu perusahaan dipengaruhi oleh kinerja individu atau pun kelompok. Suatu perusahaan akan berupaya untuk meningkatkan kinerja karyawannya dengan harapan dan tujuan perusahaan yang ingin tercapai.

Kementrian perindustrian telah menyiapkan Provinsi Jawa Barat sebagai wilayah strategis untuk pembangun kawasan industri ada sebanyak 2.381,97 hektar di wilayah utara Jawa Barat yang telah dikembangkan menjadi 10 kawasan industri baru bertaraf nasional maupun internasional. Sekitar 35\% atau 851,97 hektare dari kawasan industri baru tersebut berada di Kabupaten Karawang. Pemerintah menyiapkan Kabupaten Karawang sebagai kawasan industri modern melalui penerbitan Keppres Nomor 53 Tahun 1989 tentang Pengembangan Kawasan Industri. Ada beblerapa kawasan industri yang berskala besar yang 
Adi Komarudin, Budi Rismayadi, Suroso Vol 4 No 2

ISSN : 2541-6995

E ISSN : 2580-5517

sudah ada di Karawang, antara lain : Karawang International Industry City, Kawasan Mitra Karawang, Kawasan Surya Cipta, Kawasan Indotaisei, dan Kawasan Bukit Indah City di jalur Cikampek, dengan luas mencapai ribuan hektare. Karawang memiliki kawasan industri terluas di Indonesia, bahkan di Asia Tenggara, dengan total luas lahan industri mencapai 13,718 hektare atau 7,85 persen dari luas Kabupaten Karawang.

PT. Hasil Raya Industries merupakan salah satu perusahaan yang berada di kawasan ABC yang bergerak dalam bidang produksi kemasan plastik. Diketahui PT. Hasil Raya Industries Karawang memiliki permasalahan kurangnya kedisiplinan karyawan dan kurang bertanggung jawab terhadap pekerjaannya.

Dapat dilihat tabel dibawah PT. Hasil Raya Industries Karawang masih memiliki tingkat absensi yang tinggi. Masih banyaknya karyawan yang mangkir, alfa, izin, dan surat dokter. Karyawan yang yang kurang disiplin dapat dipengaruhi oleh beberapa faktor contohnya seperti gaji dan kompensasi, peranan atasan, adanya peraturan tertulis dan adanya sanksi nyata.

\section{Rekapan data presentase ketidak hadiran (Alfa, Izin, Surat dokter ) lebih dari $2 \%$} pada bulan Januari - Mei 2019

\begin{tabular}{|c|c|c|c|c|c|}
\hline Departemen & Januari & Februari & Maret & April & Mei \\
\hline TS & $2.30 \%$ & $3.80 \%$ & - & $2.20 \%$ & $4.30 \%$ \\
\hline PPIC & $2.10 \%$ & $2.70 \%$ & - & - & - \\
\hline PET & - & $2.40 \%$ & $3.90 \%$ & $3.40 \%$ & $3.60 \%$ \\
\hline Injection & - & $2.10 \%$ & $2.50 \%$ & $2.70 \%$ & $3.40 \%$ \\
\hline C.Room & - & $2.70 \%$ & $3.20 \%$ & $2.40 \%$ & $2.40 \%$ \\
\hline Printing & - & $2.40 \%$ & $2.10 \%$ & $2.60 \%$ & - \\
\hline Blowing & - & - & $3.70 \%$ & $3.30 \%$ & $2.50 \%$ \\
\hline QA & - & - & $2.20 \%$ & $3.70 \%$ & - \\
\hline Engineering & - & - & - & - & $2.80 \%$ \\
\hline
\end{tabular}

Sumber : HR-GA PT. Hasil Raya Industries Karawang

Dapat di lihat pada Tabel di atas Rekapan data presentase ketidak hadiran karyawan lebih dari 2\%. Tingkat Absensi karyawan PT. Hasil Raya Industries Karawang Pada bulan januari sampai Mei 2019 selalu mengalami peningkatan.

Kinerja merupakan hasil atau catatan tentang kegiatan pekerjaan yang dihasilkan dalam jumlah waktu yang ditentukan dan yang telah dicapai oleh suatu individu atau kelompok. Menurut Veithzal Rivai (2011:837) menyatakan motivasi adalah serangkaian sikap dan nilainilai yang mempengaruhi individu tuntuk mencapai hal yang spesifik sesuai dengan tujuan individu. Sikap dan nilai tersebut merupakan suatu yang invisible yang memberikan kekuatan untuk mendorong individu bertingkah laku dalam mencapai tujuan. Perusahaan harus dapat memiliki produktivitas yang baik untuk memenuhi target perusahaan yang sudah ditetapkan. 
Adi Komarudin, Budi Rismayadi, Suroso

Vol 4 No 2

ISSN : 2541-6995

E ISSN : 2580-5517

Kinerja karyawan yang baik dengan etos kerja yang tinggi akan membantu perusahaan untuk dapat memenuhi target perusahaan dan membantu perusahaan memperoleh keuntungan.

Sementara itu mengenai disiplin kerja merupakan suatu perilaku seseorang yang sadar mentaati terhadap tanggung jawab dan peraturan dari organisasi atau perusahaan. Edy Sutrisno (2016:89) menyatakan Disiplin kerja adalah perilaku seseorang yang sesuai dengan peraturan, prosedur kerja yang ada atau disiplin adalah sikap, tingkah laku, dan perbuatan yang sesuai dengan peraturan dari organisasi baik tertulis maupun tidak tertulis. Peraturan sangat penting di dalam perusahaan, oleh karena itu setiap perusahaan selalu membuat peraturan-peraturan untuk membangun karakter karyawannya dalam menciptakan tata tertib yang ada di perusahan. Kedisiplinan perusahaan dikatakan berhasil jika sebagian besar karyawan menaati peraturanperaturan yang ada.

Kedisiplinan di perusahaan tentu akan membuat lingkungan kerja yang sehat dan seimbang karena setiap karyawan menjalankan peran, fungsi dan tanggung jawabnya sesuai dengan aturan yang berlaku. Karyawan yang disiplin juga akan bekerja secara efektif dan efisien sehingga terhindar dari pemborosan waktu dan energi. Oleh karena itu, suatu perusahaan yang memiliki kedisiplinan tinggi tentu akan lebih mudah untuk mencapai tujuannya karena sistem atau aturan yang berlaku dapat dijalankan dengan baik oleh para karyawan.

Mangkunegara ( 2013:67 ) menyatakan motivasi merupakan unsur penting dalam ruang lingkup MSDM, keberadaan suatu motivasi sangat vital ketika berbicara dengan kinerja karyawan, karena kinerja yang baik di hasilkan dari motivasi yang baik. Pentingnya motivasi karena motivasi adalah hal yang menyebabkan, menyalurkan, dan mendukung prilaku manusia supaya mau bekerja giat dan antusias mencapai hasil yang optimal. Pemberian motivasi pada karyawan itu sangat perlu di perusahaan. Supaya karyawan memiliki semangat dalam bekerja dan menghasilkan target sesuai keinginan perusahaan. Bila karyawan memiliki motivasi yang tinggi akan memeberikan kontribusi yang positif terhadap perusahaan dan memiliki rasa tanggung jawab terhadap kerjaannya.

\section{Perumusan Masalah}

Berdasarkan pembatasan masalah di atas, maka rumusan masalah yang akan disajikan dalam objek penelitian ini adalah:

1. Bagaimana motivasi di PT. Hasil Raya Industries Karawang ?

2. Bagaimana disiplin kerja di PT Hasil Raya Industries Karawang?

3. Bagaimana kinerja karyawan di PT. Hasil Raya Industries Karawang? 
Adi Komarudin, Budi Rismayadi, Suroso

Vol 4 No 2

ISSN : 2541-6995

E ISSN : 2580-5517

4. Apakah terdapat hubungan motivasi dengan disiplin kerja di PT. Hasil Raya Industries Karawang?

5. Apakah terdapat pengaruh parsial motivasi terhadap kinerja karyawan pada PT. Hasil Raya Industries Karawang?

6. Apakah terdapat pengaruh parsial disiplin kerja terhadap kinerja karyawan pada PT. Hasil Raya Industries Karawang?

7. Apakah terdapat pengaruh simultan antara motivasi dan disiplin kerja terhadap kinerja karyawan pada PT. Hasil Raya Industries Karawang

\section{Tujuan Penelitian}

Berdasarkan permasalahan yang telah dirumuskan dalam rumusan masalah maka tujuan dari penelitian ini adalah:

1. Untuk mengetahui, menganalisis dan mengkaji motivasi di PT. Hasil Raya Industries Karawang.

2. Untuk mengetahui, menganalisis dan mengkaji disiplin kerja di PT. Hasil Raya Industries Karawang.

3. Untuk mengetahui, menganalisi dan mengkaji kinerja karyawan di PT. Hasil Raya Industries Karawang.

4. Untuk mengetahui, menganalisis dan mengkaji hubungan motivasi dengan disiplin kerja pada PT. Hasil Raya Industries Karawang.

5. Untuk mengetahui, menganalisis dan mengkaji pengaruh parsial moivasi terhadap kinerja karyawan pada PT. Hasil Raya Industries Karawang.

6. Untuk mengetahui, menganalisis dan mengkaji pengaruh parsial disiplin kerja terhadap kinerja karyawan pada PT. Hasil Raya Industries Karawang.

7. Untuk mengetahui, menganalisis dan mengkaji pengaruh simultan antara motivasi dan disiplin kerja terhadap kinerja karyawan pada PT. Hasil Raya Industries Karawang. 


\section{Kerangka Pemikiran}

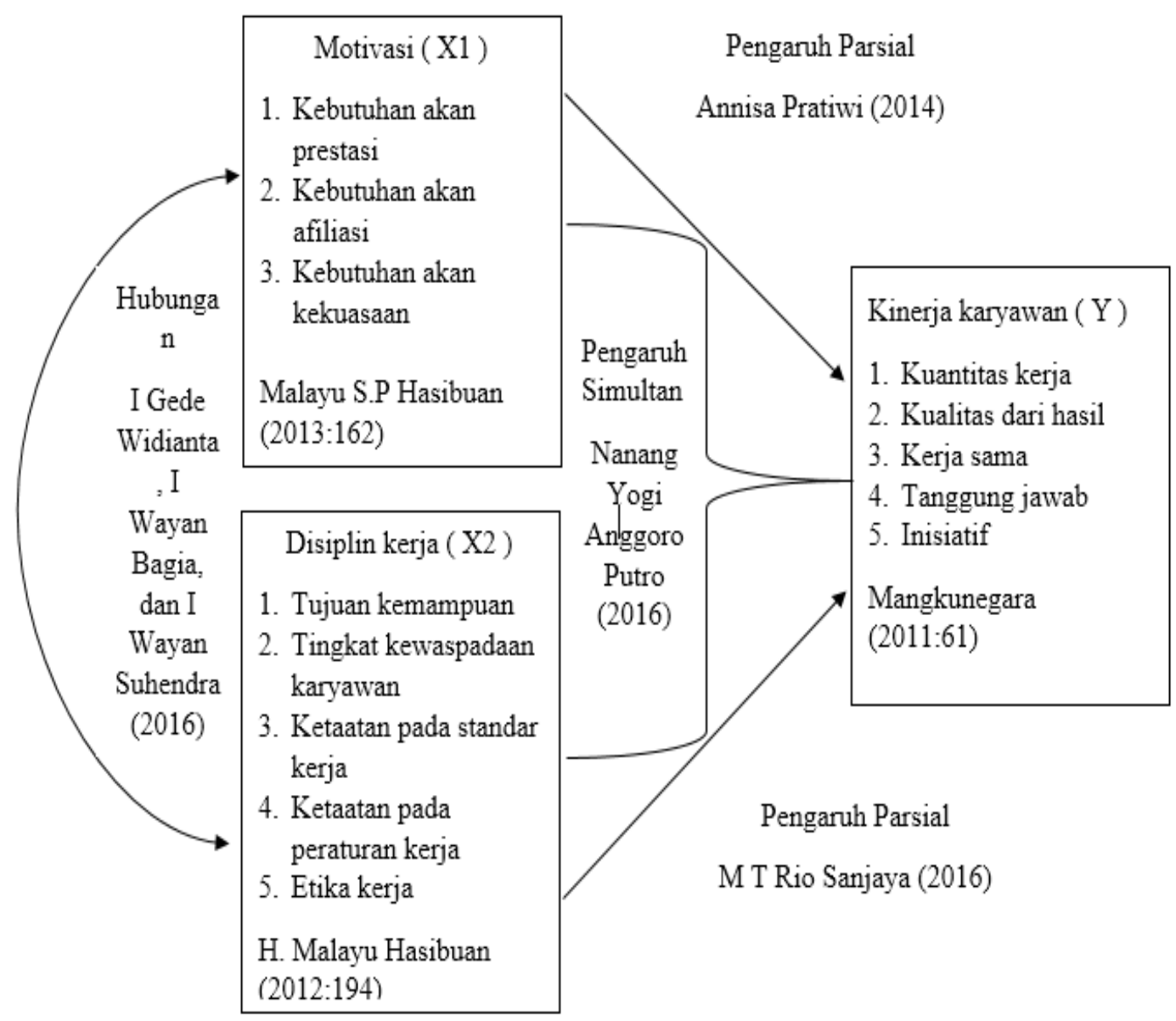

\section{Metode Penelitian}

\section{Jenis dan Lokasi penelitian}

Metode penelitian ini menggunakan pendekatan kuantitatif dengan metode yang digunakan penelitian deskriptif dan verifikatif. Teknik pengambilan sample menggunakan Accidental sampling. Dilakukan PT. Hasil Raya Industries Karawang yang berlokasi di Dusun Mangga Besar 2, Desa Walahar, Kec Klari Kawasan ABC, Karawang Timur, Walahar, Klari, Kabupaten Karawang, Jawa Barat 41371

\section{Populasi dan Sampel}

Populasi dalam penelitian ini adalah karyawan yang berada di PT. Hasil Raya Industri Karawang pada karyawan bagian injection sebanyak 116 karyawan dan karyawan bagian printing sebanyak 70 karyawan. Jumlah populasi dalam penelitian ini adalah sebanyak 186 karyawan, sehingga presentase kelonggaran yang digunakan adalah 5\% dan hasil perhitungan dapat dibulatkan untuk mencapai kesesuaian dan sampel yang menjadi responden dalam 
Adi Komarudin, Budi Rismayadi, Suroso

Vol 4 No 2

ISSN : 2541-6995

E ISSN : 2580-5517

penelitian ini sebanyak 128 orang dari seluruh total karyawan bagian injection dan printing di

PT. Hasil Raya Industries Karawang

\section{Metode pengumpulan data}

Pengumpulan data penelitian ini menggunakan metode kuesioner yang terdiri dari beberapa pertanyaan yang berasosiasi dengan variabel yang diteliti dan menggunakan metode interview dengan HRD PT. Hasil Raya Industries Karawang.

\section{Pembahasan}

\section{Analisis Deskriptif}

Analisis deskriptif menggunakan skala ordinal dan rentang skala untuk menganalisis data dengan cara menggambarkan motivasi dan disiplin kerja terhadap kinerja karyawan di PT. Hasil Raya Industries Karawang.

1. Rekapitulasi hasil total variabel motivasi, disimpulkan dari 15 pertanyaan kuesioner dengan total skor sebesar 6.892 dengan rata-rata skor 459.4 di kriteria baik berada pada posisi rentang skala 434.1 - 5361.

2. Rekapitulasi hasil total variabel disiplin kerja, disimpulkan dari 15 pertanyaan kuesioner dengan total skor sebesar 6.998 dengan rata-rata skor 466.5 di kriteria baik berada pada posisi rentang skala $434.1-536.1$.

3. Rekapitulasi hasil total variabel kinerja karyawan, disimpulkan dari 15 pertanyaan kuesioner dengan total skor sebesar 7.056 dengan rata-rata skor 477.4 di kriteria baik 477.4 berada pada posisi rentang skala 434.1 - 536.1.

\section{Analisis Verifikatif}

Analisis verifikatif terdiri dari analisis korelasi dan Path Analysis. Analisis verifikatif bermaksud untuk mengetahui hasil penelitian yang berkaitan dengan pengaruh atau besarnya Pengaruh motivasi dan disiplin kerja terhadap kinerja karyawan PT. Hasil Raya Industri Karawang. 


\section{Uji t ( Parsial )}

\section{Hasil Uji t ( Parsial )}

Coefficients $^{\mathrm{a}}$

\begin{tabular}{|c|c|c|c|c|c|c|}
\hline \multirow{2}{*}{\multicolumn{2}{|c|}{ Model }} & \multicolumn{2}{|c|}{ Unstandardized Coefficients } & \multirow{2}{*}{$\begin{array}{c}\begin{array}{c}\text { Standardized } \\
\text { Coefficients }\end{array} \\
\text { Beta }\end{array}$} & \multirow[b]{2}{*}{$\mathrm{T}$} & \multirow[b]{2}{*}{ Sig. } \\
\hline & & B & Std. Error & & & \\
\hline \multirow[t]{3}{*}{1} & (Constant) & 28.828 & 3.400 & & 8.478 & .000 \\
\hline & Motivasi & .233 & .085 & .288 & 2.747 & .007 \\
\hline & Disiplin_Kerja & .249 & .080 & .328 & 3.123 & .002 \\
\hline
\end{tabular}

a. Dependent Variable: Kinerja_Karyawan

Sumber : Hasil pengelolaan data SPSS, 2019

Berdasarkan Tabel di atas bahwa hasil uji t (parsial) diketahui bila nilai signifikansi untuk pengaruh variabel motivasi terhadap kinerja karyawan adalah 0,007 <0,05 dan nilai $\mathrm{t}$ hitung adalah $2.747>\mathrm{t}$ tabel 1,978. Nilai $\mathrm{t}$ tabel diperoleh dari rumus $\mathrm{t}=(\alpha / 2 ; \mathrm{n}-\mathrm{k}-1)=\mathrm{t}$ $(0,025 ; 126)=1,978$. Sehingga $\mathrm{H} 1$ ditolak yang berarti terdapat pengaruh motivasi terhadap kinerja karyawan. Sedangkan untuk hasil uji t (parsial) variabel disiplin kerja terhadap kinerja karyawan adalah 0,002 <0,05 dan nilai t hitung $3.123>\mathrm{t}$ tabel 1,978. Sehingga H2 ditolak yang berarti terdapat pengaruh disiplin kerja terhadap kinerja karyawan.

\section{Uji F ( Simultan )}

\section{Hasil Uji F ( Simultan )}

ANOVA $^{\mathrm{b}}$

\begin{tabular}{|ll|r|r|r|r|r|}
\hline Model & & Sum of Squares & df & Mean Square & F & Sig. \\
\hline 1 & Regression & 1405.831 & 2 & 702.915 & 30.224 & $.000^{\mathrm{a}}$ \\
& Residual & 2907.099 & 126 & 23.257 & & \\
& Total & 4312.930 & 128 & & & \\
\hline
\end{tabular}

a. Predictors: (Constant), Disiplin_Kerja, Motivasi

b. Dependent Variable: Kinerja_Karyawan

Sumber: Hasil Pengelolaan data SPSS, 2019

Berdasarkan Tabel diatas dapat dilihat bahwa nilai signifikansi untuk pengaruh motivasi dan disiplin kerja terhadap kinerja karyawan adalah $0.000<0,05$ dan nilai F hitung $30.224>$ $\mathrm{F}$ tabel 3,07. $\mathrm{F}(\mathrm{k} ; \mathrm{n}-\mathrm{k})=(\mathrm{F}(2: 128)=3,07$. Maka variabel independen motivasi dan disiplin kerja secara simultan memiliki pengaruh terhadap variabel dependen yaitu kinerja karyawan. 


\section{Koefisien Determinasi ( R Square )}

Hasil Koefisien Determinasi ( R Square )

Model Summary

\begin{tabular}{|l|r|r|r|c|}
\hline Model & $\mathrm{R}$ & R Square & \multicolumn{1}{|c|}{$\begin{array}{c}\text { Adjusted R } \\
\text { Square }\end{array}$} & $\begin{array}{l}\text { Std. Error of the } \\
\text { Estimate }\end{array}$ \\
\hline 1 & .571 a & .326 & .315 & 4.82253 \\
\hline
\end{tabular}

a. Predictors: (Constant), Disiplin_Kerja, Motivasi

Sumber: Hasil pengelolaan data SPSS, 2019

Berdasarkan Tabel diatas dapat dilihat hasil analisis diketahui nilai R Square 0.326. Hal ini berarti variabel motivasi dan disiplin kerja berpengaruh secara simultan terhadap variabel dependen yaitu kinerja karyawan sebesar $32.6 \%$. Penelitian ini menggunakan koefisien determinasi R Square, karena model yang digunakan hanya terdiri dari dua variabel independen.

\section{Analisis Korelasi}

Analisis Korelasi

Correlations

\begin{tabular}{|ll|r|r|}
\hline & & Motivasi & Disiplin_Kerja \\
\hline Motivasi & Pearson Correlation & 1 & $.715^{* *}$ \\
& Sig. (2-tailed) & & .000 \\
& $\mathrm{~N}$ & 128 & 128 \\
\hline Disiplin_Kerja & Pearson Correlation & $.715^{* *}$ & 1 \\
& Sig. (2-tailed) & .000 & \\
& $\mathrm{~N}$ & 128 & 128 \\
\hline
\end{tabular}

Sumber: Hasil pengelolaan data SPSS, 2019

Berdasarkan Tabel diatas dapat dilihat nilai signifikansi untuk korelasi motivasi dengan disiplin kerja. Dari nilai sig. disiplin kerja $0,000<0,05$. Artinya dapat dikatakan terdapat hubungan atau korelasi antara motivasi dengan disiplin kerja. Kemudian untuk nilai pearson nya sebesar 0.715 , tingkat hubungan atau korelasi antara motivasi dengan disiplin kerja saling berhubungan dengan tingkat hubungan yang kuat.

\section{Kesimpulan}

Berdasarkan hasil analisis dan pengujian dalam penelitian ini, maka dapat disimpulkan sesuai dengan hipotesis dalam penelitian sebagai berikut : 
Adi Komarudin, Budi Rismayadi, Suroso

Vol 4 No 2

ISSN : 2541-6995

E ISSN : 2580-5517

1. Motivasi pada karyawan PT. Hasil Raya Industries Karawang dengan hasil kuesioner diperoleh nilai rata-rata skor sebesar 459.4 yang berada pada rentang skala 434.1 536.1 dengan kriteria baik.

2. Disiplin kerja pada karyawan PT. Hasil Raya Industries Karawang dengan hasil kuesioner diperoleh nilai rata-rata skor sebesar 466.5 yang berada pada rentang skala 434.1 - 536.1 dengan kriteria baik.

3. Kinerja karyawan pada PT. Hasil Raya Industries Karawang dengan hasil kuesioner diperoleh nilai rata-rata skor sebesar 477.5 yang berada pada rentang skala 434.1 536.1 dengan kriteria baik.

4. Terdapat hubungan antara motivasi dengan disiplin kerja pada bagian injection dan printing di PT. Hasil Raya Industries Karawang dengan nilai signifikan sebesar 0.000 $<0.05$ dengan nilai pearson nya 0,715 .

5. Terdapat pengaruh parsial motivasi terhadap kinerja karyawan pada bagian injection dan printing di PT. Hasil Raya Industries Karawang dengan nilai sebesar $0.007<0.05$ dan nilai thitung $2.747>\mathrm{t}$ tabel 1.978 .

6. Terdapat pengaruh parsial disiplin kerja terhadap kinerja karyawan pada bagian injection dan printing di PT. Hasil Raya Industries Karawang dengan nilai sebesar $0.002<0.05$ dan nilai t hitung $3.123>$ t tabel 1.978 .

7. Terdapat pengaruh simultan motivasi dan disiplin kerja terhadap kinerja karyawan pada bagian injection dan printing di PT. Hasil Raya Industries Karawang dengan nilai signifikan sebesar $0.000<0.05$ dan nilai F hitung $30.224>\mathrm{F}$ tabel 3.07.

\section{Saran}

Berdasarkan hasil analisis dan pengujian diperoleh variabel motivasi dan disiplin kerja terhadap kinerja karyawan pada bagian injection dan printing di PT. Hasil Raya Industries Karawang. Dari hasil penelitian ini diharapkan dapat memberikan perubahan atau saran kepada pihak tertentu, beberapa saran sebagai berikut :

1. Pimpinan PT. Hasil Raya Industries Karawang harus selalu memberikan motivasi dan selalu memberikan kebutuhan karyawan. Agar tidak merasa malas, seorang karyawan atau pekerja harus termotivasi oleh hasrat yang positif dan memiliki semangat kerja yang baik.

2. Pimpinan PT. Hasil Raya Industries Karawang selalu memberikan arahan atau perhatian yang lebih terhadap karyawan yang kurang disiplin kerja untuk mendorong kesadaran karyawan yang kurang tanggung jawab terhadap pekerjaan dan agar mampu 
Adi Komarudin, Budi Rismayadi, Suroso

Vol 4 No 2

ISSN : 2541-6995

E ISSN : 2580-5517

meningkatkan disiplin kerja mereka. Selain pimpinan, pihak karyawan juga harus memiliki kesadaran diri akan kedisiplinan.

3. Penelitian ini juga dapat mempertimbangkan strategi-strategi yang yang lebih baik untuk meningkatkan disiplin kerja karyawannya dengan indiktor-indikator yang telah dianalisa. Maka membentuk faktor-faktor yang dapat dijadikan saran dan refensi.

\section{Daftar Pustaka}

\section{Referensi Buku}

A.A Anwar Prabu Mangkunegara. 2009. Manajemen sumber daya manusia. Bandung : PT. Remaja Rosdakarya

Annisa Pratiwi. 2014. Pengaruh Motivasi dan Disiplin kerja terhadap Kinerja pegawai ( Studi pada PT. Telekomunikasi Indonesia, Tbk Wilayah telkom pekalongan ). Semarang : Universitas Diponegoro

Danang, Sunyoto. (2013). Metodologi Penelitian Akuntansi. Bandung: PT Refika Aditama Anggota Ikapi.

Edi Sutrisno. 2016. Manajemen Sumber Daya Manusia. Jakarta : Prenadamedia Group.

Handoko, T. Hani. 2011. Manajemen Personalia dan Sumberdaya Manusia. Yogyakarta: Penerbit BPFE

Hasibuan, Malayu S.P. 2010. Manajemen Sumber Daya Manusia. Jakarta: PT Bumi Aksara.

Hasibuan, Malayu S.P. 2016. Manajemen Sumber Daya Manusia. Edisi Revisi. Jakarta: Penerbit PT Bumi Aksara.

Kasiram, Moh. 2008. Metodologi Penelitian. Malang: UIN-Malang Pers.

Muhammad Taufiek Rio Sanjaya. 2015. Pengaruh Disiplin kerja dan Motivasi terhadap knerja karyawan di Hotel ros in Yogyakarta. Yogyakarta : Universitas Negri Yogyakarta.

Nanang Yogi Anggoro Putro. 2017. Pengaruh Motivasi dan Disiplin kerja terhadap Kinerja Karyawan Outsourcing. Yogyakarta : Universitas Negri Yogyakarta

Rika Widaningtyas. 2016. Pengaruh Disiplin Kerja Dan Motivasi Kerja Terhadap Kinerja Karyawan (Studi pada PT. Macanan Jaya Cemerlang Klaten.). Yogyakarta : Universitas Negri Yogyakarta.

Rismayadi Budi, 2017. The Influence of Organizational Culture, Soft Skills and Leadership on Organizational Commitment and its Implication at Educator Performance (Empirical research on community learning center Karawang District, West Java). International Journal of Applied Business and Economic Research ISSN 09727302 vol 15 (20) pp:111131. 
Adi Komarudin, Budi Rismayadi, Suroso Vol 4 No 2

ISSN : 2541-6995

E ISSN : 2580-5517

Rismayadi Budi, 2018. Mediasi Komitmen Organisasi dalam Meningkatkan Kinerja Karyawan PT. Perkebunan Nusantara VIII Jawa Barat. Jurnal Manajemen \& Bisnis Kreatif Vol.4 No.1. http://doi.org/10.36805/manajemen.v4i1.386

Rismayadi, budi. 2016. Faktor-faktor yang Mempengaruhi Produktivitas Kerja Karyawan (Studi Kasus pada CV Mitra Bersama Lestari Tahun 2014). Jurnal Manajemen dan Bisnis Kreatif Vol.1 No.1 http://doi.org/10.36805/manajemen.v1i1.53

Rivai, Veithzal. 2011, Manajemen Sumber Daya Manusia untuk Perusahaan: dari Teori ke Praktik, Jakarta : RajaGrafindo Persada

Sedarmayanti. 2009. Sumber Daya Manusia dan Produktivitas Kerja. Bandung: CV Mandar Maju.

Siagian, SP. (2008). Manajemen Sumber Daya Manusia. Cetakan Kesembilan. Jakarta: Bumi Aksara.

Sugiyono. 2014. Metode Penelitian Pendidikan Pendekatan Kuantitatif, Kualitatif Dan R\&D. Bandung: Alfabeta.

Sugiyono. 2012. Metode Penelitian Kuantitatif Kualitatif dan R\&D. Bandung: Alfabeta

Sutrisno. (2009), Manajemen Keuangan Teori, Konsep dan Aplikasi, Edisi Pertama, Cetakan. Ketujuh, Penerbit Ekonisia, Yogyakarta.

S.P,Hasibuan, Malayu. 2013. Manajemen Sumber Daya Manusia. Jakarta: PT Bumi Aksara

Lupita DW. 2019. Pengaruh Lingkungan Kerja dan Budaya Kerja terhadap Kepuasan Kerja Tenaga Kesehatan (Study Kasus pada Puskesmas di Kecamatan Kota Baru), Jurnal Manajemen \& Bisnis Kreatif Vol. 5 No. 1. https://doi.org/10.36805/manajemen.v5i1.845

Veithzal Rivai. (2011). Manajemen Sumber Daya Manusia Untuk Perusahaan Dari Teori Ke Praktek. PT. RAJAGRAFINDO PERSADA, Jakarta.

\section{Referensi Online}

Sumber : Badan pusat statistik provinsi jawabarat jumlah industri besar sedang ( Unit ) di kabupaten karawang, 2003-2014. https://karawangkab.bps.go.id/statictable/2017/03/14/266/jumlah-industri-besarsedang-unit-di-kabupaten-karawang-2003-2014.html Diakses 15-Desember-2018

Sumber : Badan Pusat Statistik Kabupaten Karawang Survei Industri Besar dan Sedang (Survei IBS) Kabupaten Karawang https://karawangkab.bps.go.id/news/2018/10/16/10/surveiindustri-besar-dan-sedang--survei-ibs--kabupaten-karawang.html Diakses 15Desember-2018

Sumber : Jawa Barat disiapkan menjadi kawasan industri Kamis, 05 Oktober 2017 / 18:37 WIB https://nasional.kontan.co.id/news/jawa-barat-disiapkan-menjadi-kawasan-industri

Diakses 15-Desember-2018 
Adi Komarudin, Budi Rismayadi, Suroso Vol 4 No 2

ISSN : 2541-6995

E ISSN : 2580-5517

Sumber : Karawang pusat ekonomi https://adv.kompas.id/2017/01/24/karawang-pusatekonomi-baru/ Diakses 15-Desember-2018

Sumber : Undang-undang No.40 tahun 2007 https://www.ojk.go.id/sustainablefinance/id/peraturan/undang-undang/Pages/Undang-Undang-No.-40-tahun-2007-tentangPerseroan-Terbatas.aspx Diakses 15-Desember-2018 